\title{
The Effect of Visual and Etymological Treatments on Learning Decomposable Idioms among EFL Learners
}

\author{
Nassim Golaghaei (Corresponding author) \\ ELT Department, Faculty of Persian Literature and Foreign Languages, Roudehen Branch, \\ Islamic Azad University, Roudehen, Iran \\ E-mail: Golaghaei@riau.ac.ir \\ Sedigheh Kakolian \\ ELT Department, Faculty of Persian Literature and Foreign Languages, Roudehen Branch, \\ Islamic Azad University, Roudehen, Iran \\ E-mail: S.kakolian@gmail.com
}

Received: 12-01-2015

Published: 01-09- 2015
Accepted: 24-03- 2015

doi:10.7575/aiac.ijalel.v.4n.5p.72
Advance Access Published: April 2015

URL: http://dx.doi.org/10.7575/aiac.ijalel.v.4n.5p.72

\begin{abstract}
The present study endeavors to investigate the impact of visual and etymological treatments on learning idioms among English language learners. Seventy-nine intermediate students at Rooz Academy Language School in Babol were selected from among a total number of 116 learners based on their performances on the Longman complete course for the TOEFL test to fulfill the purpose of the study. The students were then assigned into three experimental groups. Initially, a pre-test of idiomatic expressions including 48 idiomatic items was administered to the participants in all groups. During the instructional period, the groups were taught a group of abnormally decomposable idioms through different treatments, namely, visual, etymological, and a combination of visual-etymological elaboration. At the end of the instructional period, the participants in all groups were given a posttest which was the same as the pretest. The design of this study is quasi-experimental. The data obtained was analyzed using one-way ANOVA analysis. The results of data analysis revealed that the etymological treatment was more effective than visual aids on learning idioms among intermediate English language learners. However, the visual-etymological treatment was the most effective one. The findings of this study have implications for EFL teachers, students, and materials developers.
\end{abstract}

Keywords: Visualization, Etymology, Idiom, Dual coding theory

\section{Introduction}

There are many formulaic phrases in English known as idioms that can make an English language learner want to stop learning. "What makes idioms so strange and especially troublesome for EFLs is that the whole is greater than the sum of its parts; that is, they cannot be understood simply by understanding the words composing them" (Baker, 2011, p. 3). Weinreich (1972) expatiated upon the complexity of learning idioms in terms of the idea of idiomatic expression as "a phenomenon which may be described as the use of segmentally complex expressions whose semantic structure is not deducible jointly from their syntactic structure and the semantic structure of their components" (p. 89).

Language professionals believe that in order to become proficient in English, students must include several thousand idioms into their knowledge (Bobrow \& Bell, 1973; Boers, Demecheleer, \& Eyckmans, 2004). It is estimated that there are 10,000 idioms in American English (Liu, 2000). Pollio, Barlow, Fine, and Pollio (1977) found out about 200,000 words from various sources in their study and estimated that most English speakers use almost 7,000 idioms a week, or 4.08 idioms per minute. These numbers verify the significance of idioms in spoken and written English. Despite the fact that complete mastery of idiomatic expressions seems to be approximately impossible, every language learner may experience the challenge due to the fact that these complex expressions occur frequently in English (Cooper, 1999, as cited in Coryell, 2012).

Schmitt (2010) claimed that "not only is formulaic language very common in language overall, a great deal occurs in both spoken and written forms" (p.117). Idioms as one type of formulaic language are considered to be highly attractive due to their inherent saliency. However, research pertinent to formulaic language is only gathering momentum as it is regarded to be one of the most essential fields of enquiry in the applied linguistics awaiting future research attention (Schmitt, 2010). Idiomatic expressions as one particular class of formulaic language should be taken into consideration more seriously as part of language learning due to the fact that they are normal and common in the speech and writing of native speakers (Hedge, 2000). We use idioms to make language more colorful while we are communicating our inner thoughts and emotions (Lennon, 1998). For instance, when we say 'learning a language is an uphill task' we refer to the difficulties involved in learning a language through making a clear mental picture in the listener's mind who has experienced the difficulty of walking or riding a bicycle up a steep hill.

The regularity of using idioms, particularly in original movies, lectures, academic discourse, and daily life, and the 
occurrence of the idioms in the speech and writing of native speakers clearly shows the need for ELLs to gain sufficient familiarity with idioms. The practical advantage of teaching idioms explicitly in a language course could be illustrated in terms of the idea stated by Nattinger (1988) who believes that "the instruction can help learners avoid incongruity and that having such phrases ready as whole chunks for language production assists fluency"(Nattinger, 1988, as cited in Hedge, 2000, p. 114).

Traditionally, the teaching of figurative language has been neglected in the EFL classroom due to cultural issues. Therefore, students are left to memorize chunks of language that, unless practiced frequently, will soon be forgotten (Boers, 2000). It is difficult to find reliable clues in idioms, so it is believed that the only way students could learn such expressions is by rote memorization (Boers, 2000, as cited in Baker, 2011). Evidently, it is too demanding on the part of learners to memorize the meaning of idioms literally without using the help of other tools.

Gibbs, Nayak, and Cutting (1989) divided idioms into three categories, depending on their analyzability. The first category deals with a group which is normally decomposable (transparent). In other words, the meaning of idioms could be recognized by decomposing the phrase into individual words. The second category, however, is regarded to be nondecomposable (opaque) as there is no apparent connection between the literal and figurative meaning. The final category includes abnormally decomposable (something in between transparent and opaque) idioms; it means that one can find some ways (e.g., etymological elaboration) to make a relationship between the literal and figurative meaning.

Generally speaking, learning idioms in an EFL environment could be considered in terms of three factors encompassing motivation, transparency, and imagination. Research has been done on each of these three factors to facilitate the process of teaching and learning idiomatic phrases. In language, an element is considered to be motivating when it is neither fully arbitrary nor fully predictable (Boers, Eykmans, \& Stengers, 2006). Motivating learners through raising their awareness of the metaphoric nature of idioms can have a significant effect on the retention of these phrases (Boers, 2001). "Obviously, the approach of re-awakening the literal sense or original usage of idioms and the approach of grouping idioms along conceptual metaphors complement one another" (Boers, 2006, as cited in Baker, 2011, p.174). In other words, learning the background origin of an idiom will lead to enhanced comprehension and retention.

Steinel, Hulstijn, and Steinel (2007) confirmed that high transparency would be positively correlated with results on a performance test measuring recognition of previously learned idioms. The results of their study demonstrated that the degree of transparency did not affect the participants' ability to independently and accurately reproduce the idioms. In other words, transparency is more helpful in recognizing the meaning of an idiom rather than in reproducing it.

Imagination depends on cultural factors. "Conventions differ across cultures, so that straightforward images in one culture need not be self-evident in another" (Boers \& Demecheleer, 2006, as cited in Baker, 2011, p. 256). English has a wider variety of idioms, which refer to hats or ships, while French has many more referrings to foods or sleeves (Baker, 2011).

Although there are some complexities in learning idioms, it is necessary for language learners to learn most of them. Hence, it is crucial to find an effective method for teaching idioms to improve students' learning process. Some teachers are more successful than others in teaching the same subjects. The different methods that they use could be a matter of concern. Unfortunately, there has been a lack of attention to visual and other non-linguistic resources, which would be effective in learning idioms. The concept of the visual literacy of learners has emerged as an influential concept in this regard (e.g., Galda, 1993). To improve students' motivation and interaction in class as well as in learning particular language skills and knowledge, it is recommended to use different visual-verbal aids (Danan, 1992).

Image and word are perhaps now more independent, often separated from one another, with a new relationship based on a distant connection. Benson (1997) clarified the point by stating the idea that "words are the images of things" (p. 141). Mitchell interestingly pointed out that "word and image are more like ships passing in the night, two storm-tossed barks on the sea of the unconscious signaling to each other" (as cited in McNamara, 1996, p. 27). Separating image from language in this way provides the space for education along with visualization. In fact, this system without visual aids actually will not have its role in learning.

Deeper level processing leads to higher retention (Boers, Demecheleer, \& Eyckmans, 2004). Paivio's (1986) dual coding theory basically outlines the significance of visuals in terms of the idea that the cognitive process of the human brain proceeds in relation to the processing of the information derived from the interplay of both verbal and visual elements. Accordingly, using both visual and verbal elements has additive effects on the learners' recalling procedure. There are a few studies analyzing the impact of imagery and visual aids on learning idioms (Baker, 2011; Fotovatnia \& Khaki, 2012; Saffarian, Gorjian, \& Bavizadeh, 2013).

Baker (2011) evaluated the effect of visual images and imagery on learning idioms among second language learners. It was a comparison between two experimental and control groups focusing on immediate and delayed recall of idioms, when one was presented with actual illustrations and the other was motivated to help learners develop their mental image of a scene. The results indicated that both using illustrations and encouraging self-generated imagery while explaining the etymology of idioms are helpful ways to access immediate and delayed recall of the metaphorical meanings of the idioms.

Fotovatnia and Khaki (2012) worked on the beneficial and pedagogical value of pictures in teaching both meaning and form of decomposable idioms. They investigated the effect of using pictures, Persian translation equivalents (L1), and English definitions (L2) on learning 20 decomposable and non-decomposable idioms regarding 68 Iranian TEFL undergraduates. The findings showed that the picture group outperformed the other groups in all situations. However, a significant outperformance was observed for decomposable idioms in L1 group over L2 group in the first posttest 
considering the form of idioms. The results confirmed the pedagogical value of pictures for teaching meaning and form of decomposable idioms.

Saffarian, Gorjian, and Bavizadeh (2013) investigated the effect of visual images on EFL learners' retention of body idiomatic expressions. Homogeneous groups of participants (40 males and 40 females) were selected out of 120 learners at the pre-intermediate level. They were divided into two groups as experimental and control. The experimental group was taught idioms through using visual aids. However, the participants in the control group were taught the same idioms just through verbal definitions. Finally, they concluded that applying visual images had a significant effect on learners' retention of body idiomatic expressions as the experimental group outperformed the control group.

Raising English language learners' awareness of the metaphoric nature of idioms can have a significant effect on the retention of these phrases (Boers, 2001). In other words, learning the background origin of an idiom will lead to enhanced comprehension. Besides, Boers (2001) stated that associating an idiom with its etymology has been shown to enhance retention. Ilson (1983) has defined etymology in a narrow conception. To elaborate on the term 'etymology' in its narrow sense, one should look for the term 'etyma' and cognates in order to find its source in earlier stages of the same language or other languages. The significant role of etymology in L2 vocabulary learning has long been embraced by researchers in the literature (Bagheri \& Fazel, 2010; Coryel, 2012; Zarei \& Rahimi, 2012; Zolfagharkhani \& Ghorbani Moghadam, 2011).

Bagheri and Fazel (2010) conducted a research on the effect of etymological elaboration on the EFL learners' comprehension and retention of idioms. In this experiment, fifty Iranian advanced students studying English at Bahar Language Institute, in Shiraz, were divided into two homogeneous groups of experimental and control. The participants in the experimental group of the study were exposed to the target idioms through etymological elaboration but the learners in the control group were taught the selected idioms through verbal definitions. The findings indicated that etymological elaboration considerably enhanced the learners' comprehension and retention of idioms.

Coryell (2012) conducted a research on the effectiveness of etymological elaboration as a method of teaching idioms to adolescent English language learners by using the etymological approach in an ESL classroom with 25 preadolescent and adolescent English language learners of different ages, proficiency levels, countries of origin, and native languages. It was concluded that etymological elaboration positively affects learning idioms.

Moreover, Zarei and Rahimi (2012) explored the effects of etymological explications, lexical elaboration, and contextual clues on Iranian learners' idiom comprehension and production. The results of the comprehension posttest indicated that the etymological elaboration is the most effective way of comprehending idioms; the lexical knowledge has the lowest effect on idiom comprehension. On the other hand, the results of the production posttest showed that etymological elaboration is the most effective way, contextualization stands on the second level, and finally lexical knowledge is considered to be least effective one. As a result, it can be concluded that different techniques of presentation, such as etymological elaboration, contextualization, and explicit instruction of vocabulary, are helpful in comprehending L2 idioms. In addition, etymological information was found to be more conducive to Iranian intermediate learners' idiom production compared with the other techniques involving contextualization and lexical elaboration.

Zolfagharkhani and Ghorbani Moghadam (2011) did a research on a group of Iranian upper-intermediate EFL learners to analyze the impact of etymological instruction on vocabulary learning. The results of their study revealed that the participants receiving etymological treatment (introducing prefixes, suffixes, roots, and the origins of the words) in the experimental group outperformed those in the control group, which followed its normal instruction.

As it is evident, a fairly large body of research now exists on idiomatic issues. However, most of the studies proffered to the field are devoted to using instructional treatments which are primarily directed towards using either visual (Baker, 2011; Fotovatnia \& Khaki, 2012; Saffarian, Gorjian, \& Bavizadeh, 2013) or non-visual strategies (Bagheri \& Fazel, 2010; Boers, 2001; Coryell, 2012; Zolfagharkhani \& Ghorbani Moghadam, 2011). As a consequence, no comparative analysis would be possible. The need for a comparative scrutiny becomes even more palpable as interest increases in novel approaches to idioms as one particular instance of formulaic language.

More to the point, the existing literature confirms the fact that the instructional treatments followed in almost all related studies (Bagheri \& Fazel, 2010; Baker, 2011; Boers, 2001; Coryell, 2012; Fotovatnia \& Khaki, 2012; Saffarian, Gorjian, \& Bavizadeh, 2013; Zarei \& Rahimi, 2012; Zolfagharkhani \& Ghorbani Moghadam, 2011) are based on a single modality rather than using a dual approach through combining two different modes of presentation (e.g., a combination of visual/non-visual treatments). The findings of the previous studies confirm the positive role of using a single modality in treating idioms. However, it is not yet clear how combining different approaches/modes of presentation might affect the comprehension of idioms. In actual fact, no study has been dedicated to a comparative analysis of the effect of different types of visual and non-visual interventions encompassing both single and dual modalities of presentation on the comprehension of abnormally decomposable idioms to examine which type of treatment and/or modality contribute best to the comprehension of the intended idioms. The paucity of such a comparative scrutiny justifies the need to conduct a study monitoring the effect of different types of interventions on the comprehension of idioms particularly in Iranian EFL environment. The results could be helpful in finding a more appropriate teaching method or a more preferred mode of presentation through a comparative analysis to treat multiple word phraseological units like idioms more effectively when combined with the findings of the future research.

The present study attempts to illuminate the effect of visual, etymological, and an amalgamation of visual-etymological treatments on learning a group of abnormally decomposable idioms among intermediate English language learners to 
provide a comparative view crystallizing the effect of using visual and non-visual sources and single and dual modes of presentation in comprehending particular types of idioms. The study set out to seek answer to the following research question:

Is there any significant difference among groups receiving treatments including visual aids, etymological, and visualetymological treatments in learning idioms at the level of comprehension?

On the basis of the above-mentioned question, the following null hypothesis was formulated:

There is no significant difference among groups receiving treatments including visual aids, etymological, and visualetymological treatments in learning idioms at the level of comprehension?

\section{Method}

\subsection{Participants}

The population of the present study included 79 female EFL students at intermediate level of language proficiency who were selected out of 116 learners from Rooz Academy Language School. After conducting the proficiency test, the participants whose scores were one standard deviation above and below the mean were selected. Due to the existing limitations, no randomization was used in selecting the participants. The mean age of the participants was about 24, ranging from 18 to 30, who were all female, and shared the same level of language proficiency. All the participants were native Persian speakers. Intact group method was used in this study.

\subsection{Instruments}

The following instruments were employed in the present study: a) a standard proficiency test (Longman complete course for the TOEFL test written by Deborah Phillips), b) a researcher-made pre/posttest of idioms, and c) some idiomatic pictorial clues

\subsubsection{TOEFL}

A TOEFL test was used to assess the participants' homogeneity. The test included 40 items assessing knowledge of structure and written expressions and 30 items measuring learners' reading comprehension ability. The students had 50 minutes to accomplish the tasks. The result of Cronbach's Alpha indicated a satisfactory level of overall internal consistency reliability of 0.71 .

\subsubsection{Target idioms}

It is worth mentioning that the procedure pursued in the present study required the teacher to use visual aids and etymological elaborations and the combination of both to expatiate upon the meaning of the target idioms in the three groups involved in the study. Therefore, the researcher tried to select a group of decomposable idioms that could be taught through visual aids (pictorial clues) and etymological elaborations (explanations pertinent to the history of the target idioms).

\subsubsection{Idiomatic pictorial clues}

In the present study pictures of idioms were used along with some specified procedures in the first and third experimental groups. These pictures were chosen from two websites: English daily and the free Dictionary.

\subsubsection{Etymological explanations}

Some short texts were selected from two websites as English daily and the free Dictionary to provide students with some explanations about the historical background associated with each individual idiom in the second and third groups of the study. In other words, the term 'etymological elaboration' in the present study specifically refers to the etymological history of each idiom pertinent to its origin.

\subsubsection{Pre/Posttest of idioms}

The pretest consisted of 48 items assessing knowledge of idioms at the level of comprehension. The students were free to elaborate on the meaning of idioms in Persian or in English. A pilot study was done on 30 students and the reliability analysis of the test was confirmed through test-retest method as .97. The same test was administered to the participants at the time of post testing.

\subsection{Procedure}

In order to ensure the homogeneity of the participants and determine the participants' language proficiency, the researcher administered the Longman complete course for the TOEFL test to116 students. Seventy-nine students were selected as intermediate level learners. Intact group method was used in selecting the participants. In other words, the students were non-randomly selected and then randomly assigned to three experimental groups.

Initially, the researcher provided the participants with some introductory information about the objectives of the course, the importance of learning idioms, the difficulties of learning and memorizing idioms through verbal definitions, and finally different methods of treating idioms along with the other tools.

The participants were administered a proficiency test before being exposed to the treatments. A pretest including the target idiomatic expressions was administered to the target population to assess the students' degree of familiarity with the target items in the second instructional session. Three experimental groups were involved in the present study. The participants in the groups were taught a group of abnormally decomposable idioms through different treatments, namely, visual, etymological, and a combination of visual-etymological elaboration. The instructional period lasted for ten sessions. 
Initially, the participants in the first group were provided with some handouts including some pictures depicting target idioms. In other words, the idioms were introduced to the participants via pictorial handouts which were accompanied by some examples and illustrations elaborating on the meaning of the target idioms verbally. The same procedure was followed to teach 48 idioms in ten instructional sessions which were all 60 minutes long. In other words, the students were supposed to work on 4-6 idioms in each individual session. To refresh students' minds, the teacher reviewed the previously taught idioms at the beginning of each subsequent session. The instruction in this interventionist group terminated with some oral corrective feedback provided by the teacher on the learners' performance in each instructional session. In this way, the teacher provided the students with some hints regarding the questions pertinent to the meaning of the target idioms or correct pronunciation of unfamiliar words.

The participants in the second experimental group followed a procedure different from the one pursued in the first group. They were provided with some handouts including the etymology of the idioms. In other words, the etymological history of the idioms was given to the students (e.g., 'to burn the candle at both ends' means to work long and hard, and the history of this idiom dates back to the time before the invention of electricity when people used candlelight to supply light after sunset. Therefore, if you had work to do before sunrise or after sunset you would have to use a candle. If you had to use candlelight both in the morning and at night, due to all the work you had to do, you would be burning the candle at both ends of the day). Like the first experimental group, the historical elaborations were accompanied by some examples and verbal definitions. The teacher reviewed the idioms taught previously at the beginning of each subsequent session to refresh the learners' minds. Similarly, the participants in this group were provided with some oral corrective feedback recommendations on their performances.

The procedure followed in the third experimental group was an amalgamation of the steps followed in the first and second groups of the study. The participants in this group were given some handouts including pictures of the target idioms and etymological elaborations which were followed by some examples and verbal elucidations provided by the teacher. Like the other groups, the refreshment procedure was conducted at the beginning of each subsequent session. Some oral feedback recommendations were provided on the students' performances to enhance and encourage the participants' active presence and contribution in the class.

It is worthwhile to mention the fact that the instructional treatments in the three groups involved were similar with respect to the length of the instruction, the number of idiomatic expressions taught, the number of exposures to each individual idiom, the order of presenting activities considering their level of difficulty, the refreshment procedure, and the oral corrective feedback recommendations provided by the instructor on the questions raised during the instructional period. In the thirteenth session, the participants in the three groups had to review the idioms they had learned during the instructional period. Finally, a posttest was administered to the participants in the ultimate session to assess the students' degree of achievement.

\subsection{Research Design}

The present study involved three experimental groups. It is an empirical study used to estimate the casual impact of different types of interventions on its target population. On the basis of the criteria provided by Hatch and Lazaraton (1991), the design of the current study can be defined as quasi-experimental, which has characteristics such as nonrandom assignment of students to different groups involved in the study; pretest administered to all three experimental groups; different treatments for different groups; and a posttest.

\section{Results}

\subsection{Analysis of the Proficiency Test}

To select a homogeneous sample, the participants were administered a Longman complete course for the TOEFL test (general proficiency test). Table 1 illustrates the descriptive statistics pertinent to the proficiency test.

Table 1. Descriptive statistics of the proficiency test

\begin{tabular}{ccccc}
\hline $\mathrm{N}$ & Mean & SD & Minimum & Maximum \\
\hline \multirow{2}{*}{116} & 37.7845 & 3.88488 & 30.00 & 47.00 \\
\hline
\end{tabular}

After administering the proficiency test and analyzing the scores obtained, the participants whose scores were one standard deviation above and below the mean were selected as a homogeneous sample. On the basis of the results, seventy-nine students were selected. Table 2 shows the statistical analyses.

Table 2. Descriptive statistics of the population of the study

\begin{tabular}{ccccc}
\hline $\mathrm{N}$ & Mean & SD & Minimum & Maximum \\
\hline 116 & 37.9114 & 1.81299 & 34.00 & 41.00 \\
\hline
\end{tabular}




\subsection{Descriptive Statistics}

The descriptive statistics related to the three experimental groups are shown in Table 3. A one-way ANOVA analysis was conducted to evaluate the significance of the mean differences among the groups.

Table 3. Descriptive statistics related to the three experimental groups of the study in pre/post performance

\begin{tabular}{ccccccc}
\hline Groups & Pre/Post test & $\mathrm{N}$ & Mean & SD & Minimum & Maximum \\
& & & & & & \\
\hline Visualization & Pre & 25 & 16.4000 & 2.38048 & 12.00 & 21.00 \\
& Post & 25 & 19.0000 & 2.58199 & 13.00 & 24.00 \\
\hline Etymological & Pre & 28 & 16.1429 & 1.97605 & 12.00 & 20.00 \\
Elaboration & Post & 28 & 25.0000 & 2.19427 & 20.00 & 29.00 \\
\hline Visual- & & & & & & \\
Etymological & Pre & 26 & 17.1154 & 1.79615 & 13.00 & 20.00 \\
Elaboration & Post & 26 & 29.1538 & 2.47697 & 24.00 & 34.00 \\
\hline
\end{tabular}

\subsection{Analysis of the Pretest}

The distribution of the scores in the three groups was normal as shown in the normality Table (Table 4). Based on the results, it was concluded that there was no significant difference between the mean scores of the three groups at the time of pretesting. Parametric statistics (ANOVA) was used to compare the results.

Table 4. Tests of normality

\begin{tabular}{ccccccc}
\hline & \multicolumn{3}{c}{ Kolmogorov-Smirnov $^{\text {a }}$} & \multicolumn{3}{c}{ Shapiro-Wilk } \\
& Statistic & df & Sig. & Statistic & df & Sig. \\
\hline Experimental Group 1 in Pretest & .087 & 25 & $.200^{*}$ & .977 & 25 & .811 \\
Experimental Group 2 in pretest & .140 & 25 & $.200^{*}$ & .972 & 25 & .704 \\
Experimental Group 3 in pretest & .133 & 25 & $.200^{*}$ & .962 & 25 & .446 \\
\hline *
\end{tabular}

*. This is a lower bound of the true significance

a. Lilliefors Significance Correction

Levene's statistics was used to prove the equality of group variances. As illustrated in Table 5, the Levene's F of 1.23 has a probability of .29. Since the probability associated with the Levene's F is higher than the .05 level of significance, it can be concluded that the groups enjoyed homogeneous variances.

Table 5. Test of homogeneity of variances

$\begin{array}{cccc}\text { Levene Statistic } & \mathrm{df1} & \mathrm{df} 2 & \text { Sig. } \\ 1.234 & 2 & 76 & .297\end{array}$

The probability associated with the F-observed value (.21) was higher than the significant level of .05 (Table 6). Therefore, it was concluded that the three groups belonged to the same population in terms of their knowledge of idiomatic expressions before being exposed to the treatments.

Table 6. ANOVA for analysis of variances in pretest

\begin{tabular}{cccccc}
\hline & Sum of Squares & $d f$ & Mean Square & $F$ & Sig. \\
\hline Between Groups & 13.513 & 2 & 6.756 & 1.594 & .210 \\
Within Groups & 322.082 & 76 & 4.238 & & \\
Total & 335.595 & 78 & & & \\
\hline
\end{tabular}


3.4 Analysis of the Posttest

Table 7 presents the normality of the distribution of posttest scores. Parametric statistics was used to analyze the data.

Table 7. Tests of normality

\begin{tabular}{lcccccc}
\hline & \multicolumn{3}{c}{ Kolmogorov-Smirnov $^{\mathrm{a}}$} & \multicolumn{3}{c}{ Shapiro-Wilk } \\
& Statistic & $\mathrm{df}$ & Sig. & Statistic & df & Sig. \\
\hline Experimental Group 1 in Posttest & .100 & 25 & $.200^{*}$ & .986 & 25 & .976 \\
Experimental Group 2 in Posttest & .129 & 25 & $.200^{*}$ & .974 & 25 & .750 \\
Experimental Group 3 in Posttest & .107 & 25 & $.200^{*}$ & .972 & 25 & .708 \\
\hline
\end{tabular}

*. This is a lower bound of the true significance.

a. Lilliefors Significance Correction

As shown in Table 8, the Levene's F of .29 has a probability of . 74 which is larger than the .05 level of significance. It can be concluded that the three groups enjoyed homogeneous variances in the posttest.

Table 8 . Test of homogeneity of variances

\begin{tabular}{cccc}
\hline Levene Statistic & df1 & df2 & Sig. \\
\hline .291 & 2 & 76 & .748 \\
\hline
\end{tabular}

Table 9 shows the results of the one-way ANOVA analysis related to the groups involved in the study considering their knowledge of idiomatic expressions. The probability associated with the F-observed value (.000) was lower than the significant level of .05 (Table 9). Therefore, it was concluded that there is a statistically significant difference among the groups involved considering their knowledge of idiomatic expressions after being exposed to the treatments.

Table 9. ANOVA for analysis of variances in posttest

\begin{tabular}{lccccc}
\hline & Sum of Squares & $d f$ & $\begin{array}{l}\text { Mean } \\
\text { Square }\end{array}$ & $F$ & Sig. \\
\hline Between Groups & 1326.286 & 2 & 663.143 & 113.669 & .000 \\
Within Groups & 443.385 & 76 & 5.834 & & \\
Total & 1769.671 & 78 & & & \\
\hline
\end{tabular}

\subsubsection{Post Hoc Analysis}

In order to scrutinize which two groups are different from each other, a Post Hoc analysis was conducted. The results are displayed in Table 10.

Table 10. Scheffe one-way ANOVA Post Hoc tests

\begin{tabular}{|c|c|c|c|c|c|c|}
\hline & \multirow[b]{2}{*}{ (J) Group } & \multirow[b]{2}{*}{ Mean Difference (I-J) } & \multirow[b]{2}{*}{ Std. Error } & \multicolumn{3}{|c|}{ 95\% Confidence Interval } \\
\hline & & & & Sig. & $\begin{array}{l}\text { Lower } \\
\text { Bound }\end{array}$ & $\begin{array}{l}\text { Upper } \\
\text { Bound }\end{array}$ \\
\hline \multirow{2}{*}{ Visual Group } & Etymological Group & $-6.00000^{*}$ & .66462 & .000 & -7.6594 & -4.3406 \\
\hline & $\begin{array}{l}\text { Visual-etymological } \\
\text { Group }\end{array}$ & $-10.15385^{*}$ & .67657 & .000 & -11.8431 & -8.4646 \\
\hline \multirow{2}{*}{$\begin{array}{l}\text { Etymological } \\
\text { Group }\end{array}$} & Visual Group & $6.00000^{*}$ & .66462 & .000 & 4.3406 & 7.6594 \\
\hline & $\begin{array}{l}\text { Visual-etymological } \\
\text { Group }\end{array}$ & $-4.15385^{*}$ & .65783 & .000 & -5.7963 & -2.5114 \\
\hline \multirow{2}{*}{$\begin{array}{l}\text { Visual-etymological } \\
\text { Group }\end{array}$} & Visual Group & $10.15385^{*}$ & .67657 & .000 & 8.4646 & 11.8431 \\
\hline & Etymological Group & $4.15385^{*}$ & .65783 & .000 & 2.5114 & 5.7963 \\
\hline
\end{tabular}

*The mean difference is significant at the 0.05 level

The results in Table 10 show a significant difference between the first experimental group receiving a treatment including visuals and the second experimental group receiving etymological treatment in the comprehension of idioms 
(mean difference $=6)$ and $(\mathrm{P}<0.05)$. In addition, there is a significant difference between the first experimental group and the third experimental group receiving visual-etymological treatment (mean difference $=10)$ and $(\mathrm{P}<0.05)$. Furthermore, based on the results, there is a significant difference between the second and the third experimental group (mean difference $=4)$ and $(\mathrm{P}<0.05)$. Accordingly, the visual-etymological treatment employed in the third group could be considered as the most effective one and the second treatment as etymological elaboration was found to be more effective than the first one involving visual aids.

\section{Discussion and Conclusion}

This study attempted to investigate the impact of visual, etymological, and visual-etymological treatments on learning a group of decomposable idioms in terms of the differences existing between the groups involved in the study using different types of treatments and the priority of using a single or a dual mode of representation in teaching idioms among Iranian English language learners. On the basis of the results of the study, the etymological treatment used in the second experimental group was found to be more effective than visual aids as a treatment provided in the first experimental group. The results could be theoretically attributed to the facilitative effect of the dual-coding of the input. Etymological background is likely to prompt the creation of mental images for the target expressions and helps to improve comprehension, which is in line with the findings reported by Bagheri and Fazel (2010), Boers (2001), and Coryell (2011) who reported that teaching idioms along with their literal origins to English language learners is a helpful technique for enhancing the learning of these complex expressions.

The findings of the current study indicated that the combination of visual and etymological treatment followed in the third experimental group had the most significant effect on learning idioms at the level of comprehension compared to visual and etymological treatments provided in the first and second group of the study. In other words, it was demonstrated that the etymological elaboration can be more practical if it is accompanied by the pictures of idioms. Logically speaking, trying to identify the source domains behind figurative idioms and analyzing the pictorial clues depicting the target idioms involves a certain degree of cognitive effort which would lead to greater degree of achievement. In other words, learners attempted to recognize the pictures and origins of idioms and make a relationship between the two sources. These identifications probably occur at a 'deeper' level of processing than 'shallow' rote learning. The idea could be further supported in terms of the statement provided by Boers et al. (2004) who mentioned that deep-level processing enhances memory storage. As a result, the combination of etymology and visualization is considered to be the most effective way of comprehending idioms.

In sum, the results of the comprehension posttest indicated that visual-etymological elaboration is the most effective way, etymological elaboration stands on the second level, and finally the application of visual aids is considered to be the least effective one. In other words, the etymological treatment provided in the second group had a more positive impact on the performances of the learners who were supposed to focus on the origin and sources of the idioms in comparison with the first group using visual aids. The findings in this regard denote the idea that etymological understanding can offer learners a deeper insight into beliefs, values, and practices that motivate specific linguistic expressions (e.g., idioms) through fostering their comprehension. Thus the present study suggests that etymological elaboration could be used as a reliable clue enhancing learners' comprehension of idiomatic expressions. More to the point, the findings showed that the participants in the third group who were exposed to an amalgamation of visualetymological treatment outperformed the learners in the other groups in comprehending the target idioms. Accordingly, the study comes to the conclusion that the treatment which was based on a dual mode of presentation as a combination of visual and etymological clues was found to be the most successful one in enhancing the learners' comprehension of the target idioms compared to the other groups receiving treatments including a single mode of presentation. The results obtained in this regard could be interpreted in terms of the dual-coding theory proposed by Paivio (1975) demonstrating the idea that the information that is presented both verbally and visually is stored and retrieved more easily than the information presented through a single modality.

The findings of this study have implications for EFL learners and teachers. Foreign language learners and teachers can skillfully take advantage of etymological elucidations and visual aids in treating idioms rather than resorting to rote memorization. However, etymological elaboration is regarded to be more useful in comprehending the meaning of idioms in comparison with visual aids. Besides, teachers are recommended to apply instructions including dual modes of representations as a more preferred style in teaching idioms. Furthermore, the findings of the present study can have implications for syllabus and textbook designers. "Since materials which deal with all aspects of idioms are crucial to the learning of idioms, developing such materials is strongly recommended to those who have a hand in materials development (Noroozi \& Salehi, 2013, p. 850). Accordingly, teaching materials including idiomatic expressions could become more comprehensible through using pictorial clues fostering learners' visual literacy. Besides, etymological elaborations could be effectively included to expatiate upon the meaning of complex idiomatic expressions in terms of their historical background and origin in a more tangible manner.

The present study examined the effect of etymological treatment, visual aids, and the combination of etymological elaborations and visual aids on the comprehension of a group of abnormally decomposable idioms. Further research can be carried out to investigate the impact of the interventions provided on the comprehension of other types of idioms such as, transparent, opaque, or non-decomposable ones as novel trajectories deserving deeper scrutiny. The current study evaluated the effect of different types of visual and non-visual interventions including a single and a dual modality on the comprehension of idioms; further research can be carried out investigating the impact of the abovementioned treatments on the retention and recall of the target idioms. 


\section{References}

Bagheri, M. S., \& Fazel, I. (2010). Effects of etymological elaboration on the EFL learners' comprehension and retention of idioms. Journal of Pan-Pacific Association of Applied Linguistics, 14(1), 45-55.

Baker, S. (2011). The effect of visual images and imagery on immediate and delayed recall of idioms by English language learners. (Unpublished thesis). Hamline University. Saint Paul, Minnesota.

Benson, P. (1997). Problems in picturing text: A study of visual/verbal problem solving. Technical Communication Quarterly, 6(2), 141-160.

Bobrow, S., \& Bell, S. (1973). On catching on to idiomatic expressions. Memory \& Cognition, 1, 343-346.

Boers, F. (2000). Metaphor awareness and vocabulary retention. Applied Linguistics, 21(4), 553-571.

Boers, F. (2001). Remembering figurative idioms by hypothesizing about their origin. Prospect, 16 (3), 34-43.

Boers, F., Demecheleer, M., \& Eyckmans, J. (2004). Etymological elaboration as a strategy for learning idioms. In P. Bogaards and B. Laufer (Eds.), Vocabulary in a second language: Selection, acquisition and testing (pp.53-78). Amsterdam and Philadelphia: John Benjamins.

Boers, F., Eyckmans, J., \& Stengers, H. (2006). Motivating multiword units: Rationale, mnemonic benefits and cognitive style variables. EUROSLA Yearbook, 6, 169-190.

Boers, F., Eyckmans, J., \& Stengers, H. (2007). Presenting figurative idioms with a touch of etymology: More than mere mnemonics? Language Teaching Research, 11 (1), 43-62.

Clark, J., \& Paivio, A. (1991). Dual coding theory and education. Educational Psychology Review, 71, 64-73.

Coryell, L. J. (2012). The effectiveness of etymological elaboration as a method of teaching idioms. (Unpublished doctoral dissertation). Department of Educational Theory and Practice. School of Education. University of Albany, State University of New York.

Danan, M. (1992). Reversed subtitling and dual coding theory: New directions for foreign language instruction. Language Learning, 42, 497-527.

Fotovatnia, Z., \& Khaki, G. (2012). The effect of three techniques for teaching English idioms to Iranian TEFL undergraduates. Theory and Practice in Language Studies, 2(2), 272-281.

Galda, L. (1993). Visual literacy: Exploring art and illustration in children's books. The Reading Teacher, 46(6), 506516.

Gibbs, R., Nayak, N., \& Cutting, C. (1989). How to kick the bucket and not decompose: Analyzability and idiom processing. Journal of Memory and Language, 28, 576-593.

Hatch, E., \& Lazaraton, A. (1991). The research manual: Design and statistics for applied linguistics. Boston, MA: Heinle and Heinle.

Hedge, T. (2000). Teaching and learning in the language classroom. Oxford University Press.

Ilson, R. (1983). Etymological information: Can it help our students? ELT Journal, 37 (1), 76-82.

Lennon, P. (1998). Approaches to the teaching of idiomatic language. International Review of Applied Linguistics in Language Teaching, 36, 11-30.

Liu, D. (2000). Idioms in the instructional language. Paper presented at the Thirty-fourth TESOL Annual Convention, Vancouver, Canada.

Mayer, R. E. (2002). Cognitive theory and the design of multimedia instruction: An example of the two way street between cognition and instruction. In D. F. Halpern \& M. D. Hakel (Eds.), Applying the science of learning to university teaching and beyond (pp. 55-72). San Francisco: Jossey-Bass.

Mayer, R. E. (2005). Cognitive theory of multimedia learning. In R. E. Mayer (Ed.), The Cambridge handbook of multimedia learning (pp. 31-48). Cambridge University Press.

McNamara, A. (1996). Words and pictures in the age of the image: An interview with W. J. T. Mitchell. Eye Line, 30 , 16-21.

Noroozi, I., \& Salehi, H. (2013). The Effect of the etymological elaboration and rote memorization on learning idioms by Iranian EFL learners. Journal of Language Teaching and Research, 4 (4), 845-851.

Paivio, A. (1975). Coding distinctions and repetition effects in memory. In G. H. Bower (ed.), The psychology of learning and motivation, 9, New York: Academic Press.

Paivio, A. (1986). Mental representations: A dual coding approach. New York: Oxford University Press.

Pollio, H. R., Barlow, J. M., Fine, H. J., \& Pollio, M. R. (1977). Psychology and the poetics of growth. New York: Lawrence Erlbaum.

Saffarian, R., Gorjian, B., \& Bavizadeh, K. (2013). The effect of using pictures on EFL learners' retention of body idiomatic expressions. Journal of Comparative Literature and Culture, 2(4), 150-154.

Schmitt, N. (2010). Researching vocabulary: A vocabulary research manual. New York: Palgrave Macmillan. 
Steinel, M., Hulstijn, J., \& Steinel, W. (2007). Second language idiom learning in a paired-associate paradigm: Effects of direction of learning, direction of testing, idiom image ability and idiom transparency. Studies in Second Language Acquisition, 29, 449-484.

Weinreich, U. (1972). Explorations in semantic theory. The Hague/Paris: Mouton.

Zarei, A. A., \& Rahimi, N. (2012). Idioms: Etymology, contextual pragmatic clues and lexical knowledge in focus. Germany: Lambert Academic Publishing.

Zhang, Y., \& Wu, L. (2011). A hybrid TS-PSO optimization algorithm. Journal of Convergence Information Technology, 6 (5), 169-174.

Zolfagharkhani, M., \& Ghorbani Moghadam, R. (2011). The effect of etymology instruction on vocabulary learning of upper-intermediate EFL Iranian learners. Canadian Social Science, 7(6), 1-9. 